\title{
Development and Evaluation of a Comprehensive Drought Index
}

\author{
Elaheh Esfahanian $^{\text {a }}$, A. Pouyan Nejadhashemi ${ }^{\text {a, }}$, Mohammad Abouali ${ }^{\text {a }}$, Umesh Adhikari ${ }^{\text {a }}$, Zhen Zhang \\ b, Fariborz Daneshvar ${ }^{\text {a }}$, Matthew R. Herman ${ }^{\text {a }}$ \\ ${ }^{a}$ Department of Biosystems and Agricultural Engineering, Michigan State University, East Lansing, MI 48824, USA \\ ${ }^{\mathrm{b}}$ Physical Sciences Division, Department of Statistics, University of Chicago, Chicago, IL 60637, USA \\ * Author who correspondence should be addressed. Tel.: (517) 432-7653. Email address: pouyan@msu.edu (A. Pouyan
}

Nejadhashemi)

\begin{abstract}
Droughts are known as the world's costliest natural disasters impacting a variety of sectors. Despite their wide range of impacts, no universal drought definition has been defined. The goal of this study is to define a universal drought index that considers drought impacts on meteorological, agricultural, hydrological, and stream health categories. Additionally, predictive drought models are developed to capture both categorical (meteorological, hydrological, and agricultural) and overall impacts of drought. In order to achieve these goals, thirteen commonly used drought indices were aggregated to develop a universal drought index named MASH. The thirteen drought indices consist of four drought indices from each meteorological, hydrological, and agricultural categories, and one from the stream health category. Cluster analysis was performed to find the three closest indices in each category. Then the closest drought indices were averaged in each category to create the categorical drought score. Finally, the categorical drought scores were simply averaged to develop the MASH drought index. In order to develop predictive drought models for each category and MASH, the ReliefF algorithm was used to rank 90 variables and select the best
\end{abstract}


variable set. Using the best variable set, the adaptive neuro-fuzzy inference system (ANFIS) was used to develop drought predictive models and their accuracy was examined using the 10-fold cross validation technique. The models' predictabilities ranged from $R^{2}=0.75$ for MASH to $R^{2}=0.98$ for the hydrological drought model. The results of this study can help managers to better position resources to cope with drought by reducing drought impacts on different sectors.

Keywords: Meteorological drought; Hydrological drought; Agricultural drought; Stream health drought; Drought monitoring; Drought predictive model 


\section{Introduction}

Droughts are common and recurring phenomena affecting many sectors such as agriculture, water supply, economic, social, and ecosystems (Heim, 2002). Droughts' impacts on these sectors make it difficult to develop a universal/all-embracing definition of drought, since each sector measures drought differently (Whitmore, 2000; Heim, 2002). Drought definitions are generally categorized into meteorological, agricultural, hydrological, socioeconomic, and stream health (AMS, 1997; Heim, 2002; Esfahanian et al., 2016). Meteorological drought is generally defined as a period of precipitation deficiency (several months or years) compared to a long term average (Whitmore, 2000; Heim, 2002; Mishra and Singh, 2010; Sheffield and Wood, 2011). The impacts of meteorological drought are a reduction in infiltration, runoff, deep percolation, and ground water recharge (NDMC, 2016). Agricultural drought is defined as a period of soil moisture deficiency resulting from precipitation shortage for a short period of time (few weeks duration) (Heim 2002; Sheffield and Wood, 2011). The impacts of agricultural drought are a reduction in crop biomass and yield, and plant growth (Heim, 2002; NDMC, 2016). Hydrological drought is defined as a period of deficiency in water supply due to prolong precipitation shortage (Heim, 2002). The impacts of hydrological drought are a significant reduction in streamflow, groundwater, reservoir, and lake levels (Whitmore, 2000; Heim, 2002; NDMC, 2016). The concept of socioeconomic drought, which is not the subject of this study, is based on the impacts of meteorological, agricultural, and hydrological droughts on the supply and demand of some economic goods (Heim, 2002; NDMC, 2016). Finally, stream health drought is defined as a period of deficiency in streamflow causing irreversible impacts on aquatic ecosystems (Esfahanian et al., 2016). 
Several drought indices have been developed to monitor and quantify drought. Drought indices are primarily tools to investigate drought duration, intensity, severity, and spatial extent (Mishra and Singh, 2010). Each drought index requires specific input parameters in order to measure drought. Precipitation is usually used alone or in combination with other parameters for this matter (Heim, 2002; Mishra and Singh, 2010; Sheffield and Wood, 2011). Usually for meteorological drought, precipitation is the primarily parameter (Dai, 2010). For agricultural drought, soil moisture content is commonly used with the secondary parameters of precipitation and/or evapotranspiration (Dai, 2010). For hydrological drought, streamflow is often used beside precipitation (Dai, 2010). Finally, for stream health drought, index flow, stream size, and stream temperature are used to capture fish vulnerability to drought. The index flow is defined as the median of the summer month with the lowest daily flowrate for the given period (Hamilton and Seelbach, 2011; Esfahanian et al., 2016).

However, one of the biggest challenges for using these indices is that for each drought category (e.g. meteorological, agricultural, and hydrological), dozens of indices exist. Meanwhile, each drought index requires different input parameters and uses a unique method to measure drought severity. Measuring the drought severity level (e.g. metrological) while using different methods has resulted in a wide range of responses or even contradictory conclusions. Therefore, there is need to introduce a collective understanding of categorical drought conditions, since no single index was universally accepted as the best practice in each category.

Despite the current progress in understanding the science behind droughts, there is still a need to improve drought monitoring methods, which will ultimately improve drought preparation and management practices, and reduce drought vulnerability on different sectors (Svoboda et al., 2002). This can only be achieved if one considers both categorical and overall impacts of 
drought, since focusing on one aspect can have unintended consequences on other aspects of drought. For example, a goal of a commodity stakeholder group is to develop a mitigation strategy to address drought impacts on agriculture. One solution is to use additional water from surface and ground water resources; however, this solution unintentionally worsens the impacts of drought on stream health. Therefore, a comprehensive approach to address drought problems can only be achieved if categorical and overall impacts of drought are well understood. Under this circumstance, resources can be allocated in a way that solves a categorical impact of drought while minimizing the negative impacts to other drought categories or improve the overall drought condition. Therefore, it was suggested that drought monitoring techniques can be improved by combining the existing indices to better capture the overall impacts of drought (Zargar et al., 2011). In general, the methods used for combining drought indices can be classified as: 1) decision matrix analysis (Svoboda et al., 2002; Balint et al., 2011; Zieses et al., 2014); 2) classification and regression tree (CART) analysis (Tadesse and Wardlow, 2007; Brown et al., 2008); and 3) regression technique (Keyantash and Dracup, 2004; Karamouz et al., 2009).

In the decision matrix analysis, multiple criteria are first identified to guide the final outcome. This technique was used by Svoboda et al. (2002) to create the Drought Monitor, which is a composite of meteorological drought indices (such as Palmer Drought Severity Index and Standardized Precipitation Index), and hydrologic and remote sensing information. The relationship between the Drought Monitor components and drought severity were defined using the decision matrix analysis (Scoboda et al., 2002). Additionally, the Combined Drought Index (CDI) was introduced by Balint et al. (2011), which is the combination of the Precipitation Drought Index (PDI), Temperature Drought Index (TDI), and Vegetation Drought Index (VDI). 
The weighted average of the PDI, TDI, and VDI indices were used to compute the CDI. The assigned weight for the PDI was $50 \%$ and $25 \%$ weight was assigned for each TDI and VDI indices (Balint et al., 2011). Zieses et al. (2014) developed the Global Precipitation Climatology Centre Drought Index (GPCC-DI) with $1^{\circ}$ grid spatial resolution, which is a combination of the Modified Standardized Precipitation Index (SPI-DWD) and Standardized Precipitation Evapotranspiration Index (SPEI). The GPCC-DI is calculated by taking the average of SPI-DWD and SPEI indices for each grid cell (Zieses et al., 2014).

The CART analysis is a tree-building technique, which constructs a set of decision rules to build predictive models. This technique was used by Tadesse and Wardlow (2007) to develop the Vegetation Outlook (VegOut) to predict future vegetation conditions. In this tool meteorological drought indices (Standardized Precipitation Index and Palmer Drought Severity Index), oceanic indices (such as Southern Oscillation Index, and Multivariate El Niño and Southern Oscillation Index), and satellite and biophysical data were combined using a rule-based regression tree method. A year later, Brown et al. (2008) introduced a new index named Vegetation Drought Response Index (VegDRI) based on the CART concept. In this index, meteorological drought indices (Standardized Precipitation Index and Palmer Drought Severity Index), satellite-based vegetation measures, and biophysical information (such as land cover and available soil water capacity) were combined using CART analysis in order to develop the VegDRI empirical models for different seasons.

The regression technique estimates the linear and nonlinear behavior between the dependent and independent variables. This technique was used by Keyantash and Dracup (2004) to develop an Aggregate Drought Index (ADI) that considers meteorological, hydrological, and agricultural categories of drought. In this index, six hydrologic variables including precipitation, streamflow, 
reservoir storage, evapotranspiration, soil moisture, and snow water content were aggregated using principle component analysis (Keyantash and Dracup, 2004). In addition, the Hybrid Drought Index (HDI) was developed by Karamouz et al. (2009) using this technique. This index is a combination of the Standardized Precipitation Index, the Palmer Drought Severity Index, and the Surface Water Supply Index (Karamouz et al., 2009). An artificial neural network technique was used to predict the HDI based on the three drought indices (Karamouz et al., 2009).

Given the lack of a universal drought definition in monitoring drought, the goal of this study is to introduce a universal drought definition that considers several aspects of drought including meteorological, agricultural, hydrological, and stream health. This universal definition can improve drought monitoring, which can help decision makers to better allocate the resources to reduce drought impacts on different sectors. The objectives of this study are to: (1) define categorical drought indices (meteorological, agricultural, and hydrological) based on commonly used drought indices; (2) define a universal definition of drought by combining the categorical scores; (3) select the best variable sets to construct predictive drought models; (4) develop predictive drought models for each drought category and the universal drought index.

\section{Materials and Methodology}

\subsection{Study area}

The Saginaw River Watershed is the largest watershed in Michigan, and is located in the eastern part of central Michigan (Figure 1). The watershed has a total area of $16,122 \mathrm{~km}^{2}$ and drains into Lake Huron. There are 145 subbasins in the Saginaw River Watershed, with the majority of them being warmwater streams. From the meteorological standpoint, Saginaw River Watershed has an average annual precipitation of $816 \mathrm{~mm}$ (Figure S1), and an average annual temperature of $9{ }^{\circ} \mathrm{C}$, 
which is very similar to the State average values (U.S. climate data, 2016). The region is characterized with a continental climate regime since it has a very cold winter with an average snowfall of about $110 \mathrm{~cm}$ and a warm summer with an average high temperature of $26.9{ }^{\circ} \mathrm{C}$ (ENVIRON, 2007). The wind directions are mainly from the west, west-southwest, and southwest in winter, spring, and summer and fall, respectively (ENVIRON, 2007). From the agricultural standpoint, this region is one of the most productive agricultural regions in Michigan in which corn, soybean, and sugar beets are the main crops (USDA-NASS, 2011; Selzer et al., 2014). From the hydrological standpoint, this region is a rich resource for recreation activities such as walleye fisheries (Selzer et al., 2014). The flow rate in the Saginaw River is controlled by runoff from its drainage area and seiche-related water level fluctuations on the Saginaw Bay with an average discharge rate of $115 \mathrm{~m}^{3} / \mathrm{s}$ (ENVIRON, 2007). In general, flow is high during spring while reducing to the lowest level during summer. The value of recreational activities in

this region is around $\$ 15.9$ million annually (Selzer et al., 2014). From the stream health standpoint, the Saginaw River Watershed provides habitats for more than 90 fish spices and it has the largest contiguous freshwater costal wetland in the United States (PSC, 2012; Selzer et al., 2014). However, the rapid industrial and population growth in the $20^{\text {th }}$ century have caused significant ecosystem degradation in this region (Selzer et al., 2014).

Figure 1.

\subsection{Modeling process}

The goal of this study is to define a new combined drought index which considers different aspects of drought including meteorological (M), agricultural (A), stream health (S), and hydrological $(\mathrm{H})$. This new drought index is named MASH. The process started by calculating 13 drought indices for all subbasins within the Saginaw River watershed. For each drought 
category, except stream health for which only one drought index exists, four commonly used drought indices were selected. The modeling process consists of two phases: The Categorical Drought Index Development phase in which the overall drought index is defined for each drought category and MASH, and the Drought Model Development phase in which predictive models are developed to estimate the categorical drought indices and MASH (Figure 2).

In the Categorical Drought Index Development phase, all 13 drought indices are calculated on a monthly basis for 145 subbasins within the study area over a 34-year-period (1979-2012). In order to make the indices comparable within each category, the value of each index was classified and then normalized using a linear scaling technique. Next within each category (meteorological, agricultural, and hydrological) cluster analysis was performed to calculate the categorical drought index based on the average value of the closest three out of four indices. The MASH index then was calculated by averaging the categorical drought indices.

In the Drought Model Development phase, the ReliefF algorithm was used for ranking the input variables for the drought predictive models (three categorical and one MASH). For each drought predictive model, all combinations of the top two and three variables (out of the top five ranked variables) were used for the model development using the adaptive network-based fuzzy inference system (ANFIS). The accuracy of the developed models were then validated using the 10-fold cross validation technique.

Figure 2.

\subsection{Categorical drought index development}

In this section, the common drought indices within each drought category are defined. These indices will be later used for development of the categorical and universal drought indices. 


\subsubsection{Meteorological Drought Indices}

Palmer Drought Severity Index (PDSI), Rainfall Deciles (RD), Standardized Precipitation Index (SPI), and Reconnaissance Drought Index (RDI) were the four meteorological indices selected for this study. These indices are commonly used to monitor meteorological drought (Keyantash and Dracup, 2002; Hayes, 2006; Dai, 2010; Sheffield and Wood, 2011; Moorhead et al., 2015). The reference, input parameters, and description of each of these indices are presented in Table S1. All of these indices use precipitation as the input parameter to monitor drought (Hayes, 2006). The PDSI uses additional parameters such as temperature, available soil water content, and solar radiation while the RDI uses potential evapotranspiration.

The RD, SPI, and RDI are computationally less complex compared to PDSI, since the latter needs a greater number of parameters for calculation (Hayes, 2006). The PDSI considers evaporation by comparing the actual soil moisture (precipitation plus available soil water content) to the soil moisture demand of a region (potential evapotranspiration) (Heim, 2002; Dai, 2010). On the other hand, the RD and SPI do not consider evaporation (Dai, 2010). The RDI is more comprehensive compared to the SPI, due to considering the balance between the input (precipitation) and the output (potential evapotranspiration) (Tsakiris and Vangelis, 2005; Zargar et al., 2011). Indices such as the RD, SPI, and RDI require long-term precipitation data; however, the PDSI does not need long-term climatological data (Dai, 2010). The SPI and RDI can be measured for different time scales such as 1-month, 3-months, 6-months, up to 48 months, yet RD and PDSI cannot be used for different time scales (Keyantash and Dracup, 2002; Tsakiris and Vangelis, 2005; Dai, 2010). Based on several studies conducted on drought indices, it was concluded that the SPI is more preferable compared to PDSI (Guttman, 1998; Hayes et al., 1999; Hayes et al., 2000). This was due to SPI's simplicity and clear assessment of drought 
intensity, duration, and spatial extent (Hayes et al., 2000; Zargar et al., 2011). However, the PDSI was indicated to be very complex and difficult to interpret (Zargar et al., 2011). This was supported by another study that evaluated the performance of meteorological drought indices based on six criteria of robustness, tractability, transparency, sophistication, expendability, and dimensionality (Keyantash and Dracup, 2002). The results of this study indicated that among all meteorological drought indices, the SPI and RD have the highest rank, and the PDSI has the lowest rank (Keyantash and Dracup, 2002; Zargar et al., 2011). The RDI was not included in this comparison.

\subsubsection{Agricultural Drought Indices}

For this study, the Palmer Moisture Anomaly Index (Z-index), Soil Moisture Deficit Index (SMDI), Evapotranspiration Deficit Index (ETDI), and Soil Water Deficit Index (SWDI) were selected as the agricultural drought indices. The Z-index is one of the most widely used indices for capturing agricultural drought (Dai, 2011). The SMDI and ETDI have high spatial and temporal resolutions in monitoring agricultural drought (Narasimhan and Srinivasan, 2005). The SWDI was recently introduced, and uses soil water observations to analysis agricultural drought (Martinez-Fernandez et al., 2015). The reference, input parameters, and description for each of these indices are presented in Table S2. The SMDI only uses the soil moisture, and the ETDI only uses evapotranspiration as the input parameters to estimate drought condition (Narasimhan and Srinivasan, 2005). In addition, the SWDI only uses soil water storage parameters such as soil moisture, available soil water content, field capacity, and wilting point for agricultural drought assessment (Martinez-Fernandez et al., 2015).

The Z-index is more computationally intensive compared to the other three indices, since it considers precipitation, temperature, available soil water content and other parameters (a total of 
eight variables) in its calculation (Palmer, 1965; Jacob et al., 2013; Ficklin et al., 2015). In contrast, the SMDI and ETDI only use soil moisture and evapotranspiration (potential and actual), respectively (Narasimhan and Srinivasan, 2005). However, the challenging part for calculating the SMDI will be acquiring soil moisture data (Moorhead et al., 2015). The SWDI is more comprehensive compared to SMDI in capturing soil moisture deficit, since it uses several soil parameters while the SMDI only uses one parameter (soil moisture). The spatial and temporal resolutions of SMDI and ETDI are higher compared to the Z-index. The Z-index has been used with coarse spatial resolution of 7,000 to $100,000 \mathrm{~km}^{2}$ and monthly temporal resolution (Narasimhan and Srinivasan, 2005). However, the spatial resolution for the Z-index is changeable and higher resolution can be used. On the other hand, the SMDI and ETDI have high spatial resolution of $16 \mathrm{~km}^{2}$ and a weekly temporal resolution (Narasimhan and Srinivasan, 2005). The SMDI and ETDI with finer spatial and temporal resolutions can improve monitoring soil moisture and evapotranspiration deficits compare to the Z-index.

\subsubsection{Hydrological Drought Indices}

In this study the Palmer Hydrological Drought Index (PHDI), Flow Duration Curve (FDC), Standardized Runoff Index (SRI), and Water Balance Derived Drought (WBI) were used as the hydrological drought indices. The PHDI is one of the most commonly used indices to monitor hydrological drought (Dai, 2011) while the FDC, SRI, and WBI were more recently developed (Tallaksen and van Lanen, 2004; Shukla and Wood, 2008; Vasiliades et al., 2011). The reference, input parameters, and description for each of these indices are presented in table S3. These new indices only use runoff to monitor hydrological drought (Tallaksen and van Lanen, 2004; Shukla and Wood, 2008; Vasiliades et al., 2011). However, the PHDI is more 
computationally intense, since it uses eight different climatological data for calculating hydrological drought (Palmer, 1965; Jacob et al., 2013; Ficklin et al., 2015).

The SRI and WBI need long-term (over 20 years) historical data to be reliable for drought monitoring. However, the PHDI and FDC do not require long-term streamflow data. The normalization approach is used to calculate the SRI and WBI indices, which is similar to the SPI index (Shukla and Wood, 2008; Vasiliades et al., 2011). The SRI and WBI use different distributions in order to normalize the runoff data. The SRI uses a log normal distribution while the WBI uses the Box-Cox transformation (Shukla and Wood, 2008; Vasiliades et al., 2011). Then the transformed data are standardized into a normal distribution with a mean of zero and standard deviation of one (Shukla and Wood, 2008; Vasiliades et al., 2011). However, for the FDC calculation the threshold level approach is used (Tallaksen and van Lanen, 2004; USEPA, 2011). In this approach, the threshold levels are defined based on a specific percentile flow for a certain period of time. The streamflow data for the selected time intervals are ranked, and their exceedance probabilities are calculated (Tallaksen and van Lanen, 2004; USEPA, 2011). Then based on the defined thresholds, the wet and dry condition of the region can be determined.

\subsubsection{Stream Health Drought Index}

In contrary with other drought indices, only one index was defined for the stream health drought. The reference, input parameters, and description for the stream health drought index is presented in Table S4. This index uses long-term median and average flow rate to monitor stream health drought (Esfahanian et al., 2016). The index was developed based on the concept of the regionalscale habitat sustainability model (Zorn et al., 2008; Hamilton and Seelbach, 2011), which predicts the effect of flow reduction on fish assemblages during the low flow period that is the most stressful for the fish assemblage. In the regional-scale habitat sustainability model, an index 
flow was defined as a threshold to evaluate the proportion of fish assemblage reduction (Zorn et al., 2008). The index flow is the median of the daily flow rate values for the summer month (July, August, and September) with the lowest average flow rate within a given period (Hamilton and Seelbach, 2011). The stream health drought conditions were defined considering different percent of index flow reduction, stream size, and stream temperature (Zorn et al., 2008; Esfahanian et al. (2016). The general associated ranges of drought classes are presented in table S4. The index flow was calculated for each stream in the study area. Then it was multiplied by the general associated drought ranges to obtain the specific drought class for each stream on a monthly basis.

The stream health drought index model uses monthly median flows and average flow rates as the input data to predict the stream health drought condition for the future month based on the river continuum concept (Vannote et al., 1980; Esfahanian et al., 2016). The input data to the stream health drought index model can either be obtained directly by monitoring (e.g. United States Geological Survey-National Water Information System) or indirectly through hydrological modeling (e.g. using the Soil and Water Assessment Tool-SWAT (Arnold et al., 1998)). However, the initial calculation of the index flow required long-term flow data and understanding of the stream habitat that can limit the use of this technique in regions where rich datasets are not available.

\subsubsection{Input parameters}

The name, source, and description of all parameters used to estimate the 13 aforementioned drought indices are presented in Table S5. In general, seven different sources were used to obtain the input data for drought indices calculation. The precipitation and temperature data were obtained from the National Climatic Data (NCDC) stations (16 precipitation and 13 temperature 
stations). The National Elevation Dataset of the US Geological Survey (USGS) with a spatial resolution of $30 \mathrm{~m}$ was used to obtain elevation data (NED, 2014). The soil characteristic data such as available soil water content were obtained from the Natural Resources Conservation Service (NRCS) Soil Survey Geographic (SSURGO) database (NRCS, 2014). The data warehouse provided by Abatzolgou (2013) was used to obtain solar radiation, wind speed, and relative humidity data. The average annual albedo data were obtained from Barkstrom (1984). The intermediate palmer parameters such as potential evapotranspiration, and index of drought severity were obtained from the tool developed by Jacob et al. (2013) and modified by Ficklin et al. (2015), which is operating within MATLAB environment. The remaining hydrological and climatological parameters such as actual and potential evapotranspiration, soil moisture, field capacity, available soil water content, and stream flow were obtained from a hydrological model (SWAT), which is developed by the USDA Agricultural Research Service (USDA-ARS) (Arnold et al., 1998). Sensitivity analysis was performed on SWAT to better understand the important parameters that should be used for model calibration. The analysis was performed using Sequential Uncertainty Fitting (SUFI2) embedded in the SWAT-CUP program (Abbaspour, 2015). The top ranked parameters include the threshold depth of water in the shallow aquifer to reach the root zone (REVAPMN), the biological mixing efficiency (BIOMIX), the surface runoff lag time (SURLAG), the groundwater delay (GW_DELAY), and the channel hydraulic conductivity (CH_K2). This physically based model was calibrated and validated using observed monthly stream flow data for nine USGS gauging stations. The calibration period was from 2001 to 2005 , and the validation period was from 2006 to 2010 . Three statistical methods were used to evaluate the model calibration and validation performances. These methods are Nash-Sutcliffe efficiency (NSE), root mean square error observations standard deviation ratio (RSR), and percent bias (PBIAS). The model performs satisfactorily if NSE $>0.5$, RSR $\leq 0.7$, and PBIAS $<$ 
\pm 25 on a monthly time step (Moriasi et al., 2007). The calibration and validation information for each USGS streamflow gauging station is provided in table S6. The locations of each USGS streamflow gauging stations are presented in Figure S2.

\subsubsection{Transformation and Clustering}

As shown in Tables S1 to S4, each drought index has different associated ranges, and classifications of drought magnitude. Some of the indices are categorized into more detailed classes compared to others that have a boarder classification of wet and dry conditions. For instance, the PDSI is classified into 11 wet and dry categories. However, the SPI is classified into seven dry and wet categories. In order to make the indices comparable, a similar classification should be used. In this study, four drought categories including initial, moderate, severe, and extreme drought were identified and associated ranges were assigned to them (Table S6). Similarly, four non-drought categories including initial, moderate, severe, and extreme wet conditions were identified and associated ranges were assigned to them (Table S7).

In order to obtain the overall drought score for each category and MASH, the drought indices were normalized to become comparable (Tables S6 and S7). The linear scaling technique was used to assign eight ranges ( -100 to $<-75,-75$ to $<-50,-50$ to $<-25,-25$ to $<0,0$ to $<25,25$ to $<50$, 50 to $<75$, and 75 to 100 ) based on the defined classification (initial, moderate, severe, and extreme). Based on the normalized ranges, the calculated values for each drought index were transformed into a number between -100 and 100. The following equations ( 1 to 8 ) were used to normalize each drought index:

Initial Drought

$$
I_{N}=\frac{I-a}{b-a}(25-0)
$$


Moderate Drought

$$
I_{N}=\frac{I-b}{c-b}(50-25)+25
$$

Severe Drought

$$
I_{N}=\frac{I-c}{d-c}(75-50)+50
$$

Extreme Drought

$$
I_{N}=\frac{I-d}{e-d}(100-75)+75
$$

Initial Wet

$$
I_{N}=\frac{I-a}{b-a}(0-25)
$$

Moderate Wet

$$
I_{N}=\frac{I-b}{c-b}(25-50)-25
$$

Severe Wet

$$
I_{N}=\frac{I-c}{d-c}(50-75)-50
$$

Extreme Wet

$$
I_{N}=\frac{I-d}{e-d}(75-100)-75
$$

where, $I_{N}$ is the normalized drought/wet index value, $I$ is the initial drought/wet index value, $a$ to

$b$ are the associated range of the initial drought/wet category, $b$ to $c$ is the associated range of the moderate drought/wet category, $c$ to $d$ are the associated range of the severe drought/wet category, and $d$ to $e$ are the associated range of the extreme drought/wet category.

In order to obtain the categorical drought scores for each subbasin, cluster analysis was performed. The cluster analysis allows for identifying a more collective drought score since there is not a universal definition of drought within each category. The cluster analysis finds the closest three indices out of four within each category (except the stream health index) for each month and then finds the average of three closest indices. In the case that there is a tie between two sets of three indices, the average of four indices is calculated.

\subsubsection{Aggregation}

Since no preference was considered for each drought category, the simple averaging method was used to calculate the MASH score (equation (9)) for each month over the 34 year period: 


$$
M A S H=\frac{C M I+C H I+C A I+C S H I}{4}
$$

where, $M A S H$ is the overall score of all four categorical drought scores, $C A I$ is the categorical agricultural score, $C H I$ is the categorical hydrological score, CSHI is the categorical stream health score, $C M I$ is the categorical meteorological score. The MASH score is a number between -100 and 100.

\subsection{Drought indices comparison}

A paired T-test is frequently adopted for testing the difference between paired observations for two variables. However, the usual T-test assumes the samples are independent and normally distributed. The independence assumption can be violated due to the fact that observations within the same location (subbasin) can be correlated. Similarly, the observations during the same recorded time (year/month) can be correlated. Therefore, we consider a model-based approach to test the mean difference by adjusting for such correlations. We use a linear mixed-effects model (Pinheiro and Bates, 2006) with two nonnested random effects on location and recorded time respectively to model the difference:

$$
Y_{i j}=\mu+\alpha_{i}+\beta_{j}+\varepsilon_{i j}
$$

where, $Y_{i j}$ is the observed difference between two variables for subbasin $i=1,2, \ldots, N=145$ and $j=1,2, \ldots, T=408$ recorded time (month) from 1979 to 2012. The parameter $\mu$ represents the grand mean of the difference $Y_{i j} . \alpha_{i}$ is a random effect on the subbasin to account for the correlation between observations within the same subbasin, with its dispersion parameter measuring the variability due to subbasin. $\beta_{j}$ is a random effect on the recorded time to account for the correlation between observations within the same recorded time, with its dispersion 
parameter measuring the variability due to recorded time. $\varepsilon_{i j}$ is the residual with its dispersion parameter measuring the unexplained variability. By adjusting for the correlations, our goal is to test the null hypothesis $\mu=0$ versus the alternative hypothesis $\mu \neq 0$. The associated $p$-value is calculated based on Satterthwaite's approximations for the degree of freedom and is implemented in the R package lmerTest (Kuznetsova et al., 2016). We applied the method to each pair of drought indices.

\subsection{Drought model development}

In this phase, drought predictive models were developed for three of the drought categories (metrological, hydrological, and agriculture) and MASH. It is important to note that no predictive drought model is needed for stream health because the stream health drought index can be directly calculated from observed streamflow data. In order to select the best variable set for the drought models, the ReliefF algorithm was used. Then the top five ranked variables were incorporated into the adaptive neuro-fuzzy inference system (ANFIS). Finally, the 10-fold cross validation technique was used to determine the validity of the predictive models.

\subsubsection{Parameter selection}

The ReliefF algorithm is a commonly used feature selection method, which is capable of handling data with strong dependencies (Kononenko, 1994; Robnik-Sikonja and Kononenko, 2003). This method is the improved version of the Relief algorithm enabling feature selection for numerical datasets (Kira and Rendell, 1992b; Kononenko, 1994; Robnik-Sikonja and Kononenko, 2003). In this method, the independent variables are ranked based on their relevance in predicting the dependent variable (Kononenko, 1994; Robnik-Sikonja and Kononenko, 2003). With $k$ being the number of each neighborhood samples, this algorithm searches for $k$ of the nearest neighbors of the same class, also known as nearest hits, and $k$ of the nearest neighbors of 
the different class, also known as nearest misses, for each sample. Therefore, there will be $k$ nearest hits and $k$ nearest misses for each sample. The relevance of the variables for all samples is defined using the following equation:

$$
W_{i}=W_{i}-\frac{1}{k} \sum\left|s_{i}-H_{i}\right|+\frac{1}{k} \sum\left|s_{i}-M_{i}\right|
$$

where, $W_{i}$ is the weight of the feature, $k$ is the number of each neighborhood samples, $s_{i}$ is the ith sample, $H_{i}$ is the k nearest hits to $s_{i}$, and $M_{i}$ is the k nearest misses to $s_{i}$.

The input data, categorical meteorological, agricultural, hydrological, and the MASH scores were used in the ReliefF algorithm to rank the best variable set. The top five ranked variables were used to develop the predictive drought models.

\subsubsection{Development of predictive drought models}

The categorical and MASH predictive drought models were created using the Sugeno-type fuzzy inference system (Takagi and Sugeno, 1985). The Sugeno-type fuzzy inference system has been widely used in modeling complex environmental and ecological systems, water resource problems, and drought forecasting (El-Sebakhy et al., 2007; Kisi et al., 2006; Bacanli et al., 2009; Einheuser et al., 2013a, Hamaamin et al., 2013; Woznicki et al., 2015; Woznicki et al. 2016). In this technique, graphical membership functions (MFs) are used to represent the degree of membership of the input variables. Degree of memberships of zero and one represent no and full membership, respectively (Kaehler, 2006).

There are some challenges associated to modeling with fuzzy logic such as defining the membership function parameters and designing fuzzy rules (Bacanli et al., 2009). Due to these limitations, the ANFIS method was developed to improve the development of membership 
functions. ANFIS is a combination of fuzzy logic and artificial neural network (ANNs) methods which has the benefits of both methods in one framework (Bacanli et al., 2009). This multi-layer network uses ANNs to create MFs and minimize the output errors to be used in fuzzy logic (Jang, 1993).

The Fuzzy Logic Toolbox in MATLAB R2015b was used to develop ANFIS models (MathWorks, 2015). Five membership function shapes in combinations of 2, 3, or 4 were tested for each variable. The membership function shapes are triangular, trapezoidal, generalized bell, Gaussian, and Gaussian composite. The first two functions are linear and the remaining functions are nonlinear and fit better for ecological data (Marchini et al., 2011). Furthermore, there are two possible outputs for the membership functions, linear and constant. All possible combinations of two and three sets of variables out of top five ranked were used to create the predictive models. Information describing all of the possible combinations are presented in Table 1. As a result, a total of 3,600 models were created for the three drought categories and MASH adding up to 14,400 models.

The 10-fold cross validation technique was used to train, test, and select the best ANFIS model. The dataset is randomly and equally divided into 10 exclusive subsets (folds) in the 10 -fold cross validation. Nine folds of the data are used for training (90\%) and the remaining one fold is used for testing $(10 \%)$. This process was repeated 10 times and each time the fold used for testing was substituted with one of the folds used in model training. Therefore, in this process the total of 144,000 models were trained and tested in order to select the best ANFIS models for the three drought categories and MASH. The final selection is based on the lowest Root Mean Square Error (RMSE) of the 10-fold cross validation. In case of a tie in RMSE, $R^{2}$ was used as tiebreaker. 


\section{Table 1.}

\subsection{Identifying the drought vulnerable areas}

Identifying the drought prone areas is an important step toward developing mitigation strategies and actions to reduce drought impacts and vulnerability (Wilhite et al., 2014). In this section of the study, the goals are: 1) to demonstrate the application of MASH in identifying drought prone areas in the Saginaw River Watershed and 2) to compare the drought prone areas identified by MASH against drought prone areas identified by categorical drought indices. Drought prone areas were divided into three equal intervals of high, medium, and low priorities based on the number of drought events that occurred over the period of study (1979 to 2012).

\section{Results and Discussions}

\subsection{Statistical Analysis of Drought Indices}

As discussed in the introduction section, there is no universal drought definition even within each drought category. This means that different drought indices, even in the same category (e.g. meteorological) can report diverse level of drought severity. In order to test this hypothesis, four commonly used drought indices in each category (methodological, hydrological, and agricultural) were tested using a linear mixed-effects model (Pinheiro and Bates, 2006). This model tests the mean difference between each pair of drought indices within each category. The results of this statistical analysis for each drought category are presented in Table 2. Each number in this table indicates the p-value between each pair of indices. p-values larger than 0.05 (in red) show no significant mean differences.

In the meteorological category, none of the indices had a significant mean difference. The similarity between the meteorological indices can be due to having similar approaches in 
monitoring meteorological drought. In most cases, a long-term historical precipitation record is used to calculate drought severity. In the hydrological category, only the SRI and WBI indices have a significant mean difference. This difference can be explained by examining the different normalization approaches used to calculate the hydrological drought for each index. SRI fits the historical runoff records into a log normal distribution, and then transforms it a standardized normalized distribution. However, the WBI uses the Box-Cox for transforming of the historical runoff records, and then transforms it into a standardized normalized distribution. In the agricultural category, the SMDI and ETDI are the only indices that have no significant mean difference. The similarity between the SMDI and ETDI can be due to using the same crop growth model in their calculations. Overall, in the meteorological and hydrological categories most of the pairs showed similar behavior. However, in the agricultural category only one pair out of six pairs showed similar behavior.

For all drought indices, the mean difference and standard deviation values are presented in Table S6. For the meteorological indices (PDSI, RD, SPI, and RDI), the mean differences are small ranging from -1.32 to 1.29 ; however, the standard deviations are large and ranging from 10.72 to 58.97. Similarly, for the hydrological indices (PHDI, FDC, SRI, and WBI), the mean differences are small ranging from - -0.06 to 1.97 ; and the standard deviations are large and ranging from 8.81 to 47.54. Therefore, despite the fact that for both meteorological and hydrological indices the long-term averages can be very similar; the results for individual events can be quite different. Finally, for the agricultural indices (Z-Index, SMDI, ETDI, and SWDI), the mean differences and standard deviations are both large ranging from -5.56 to 67.12 , and 34.53 to 44.13 , respectively. This indicates that there is a large contradiction between the agricultural indices for both long-term averages and individual events. 
Regarding the categorical drought indices, CMI is not significantly different from other meteorological indices. While the mean varies from -0.15 to 1.14 , the standard deviation is large ranging from $14.45(\mathrm{RDI})$ to $50.34(\mathrm{RD})$. The categorical hydrological index (CHI) does not have any significant mean difference with the PHDI, FDC, and SRI since the mean difference ranges of 0.12 to 1.56 , and the standard deviation ranges from 9.35 to 36.34 . However, similar to the CMI, the standard deviation is large, which can be misleading. In fact, with each drought level having a range of 25 the $\mathrm{CHI}$ could be off by up to two drought levels. Comparing the $\mathrm{CHI}$ to with all other categorical and drought indices, no significant mean difference was observed with any of the meteorological indices and the Z-index. The meteorological indices have a mean difference range of 0.03 to 1.36 , and a standard deviation range of 32.69 to 44.52 with the CHI. In addition, the Z-index mean difference and standard deviation with the $\mathrm{CHI}$ are 0.73 and 32.12 , respectively. Therefore, it can be concluded that $\mathrm{CHI}$ can be a good alternative to both meteorological and hydrological drought indices but caution should be exercised due to the possibility of large standard deviation. The categorical agricultural index (CAI) has no similarity with any of the agricultural indices or other drought indices. This implies that diversity in defining agricultural indices are much larger compare to hydrological and metrological drought categories. Finally, the categorical stream health index (CSHI) has no similarity with any of the drought indices, which implies that the CSHI should be separately calculated and combined with existing indices to capture the overall drought condition.

\subsection{Categorical Drought Indices}

Results from the Categorical Drought Indices analysis are summarized in Table 3. What is unique about this analysis is that in contrary with similar studies (Scoboda et al., 2002; Karamouz et al., 2009) the indices were not combined to develop a new index for each category; 
rather the most common drought definition in each category was identified by averaging the closest drought scores. This helped define the near universal drought index known as the categorical drought index.

In the meteorological category (Table 3), the combination of PDSI, SPI, and RDI was identified as the most selected combination in $62.7 \%$ of the time. Moreover, the combination of all four indices was the least selected combination $(0.02 \%)$. In the hydrological category, the combination of FDC, SRI, and WBI was identified as the most selected combination (49.68\%). The PHDI, SRI, and WBI combination was selected as second with a small difference (7.96\%) from the first ranked set. The least selected combination was the all four indices combination $(0.01 \%)$. Finally, in the agricultural category, the Z-index, SMDI, and ETDI combination was identified as the most selected combination for $69.44 \%$ of the time. The Z-index, ETDI, and SWDI combination was selected as a distance second (12.21\%) and the remaining combinations were selected about $9 \%$ of the time. The combination of all four indices was not selected at all. Therefore, it can be concluded that the RD, PHDI, and SWDI are the most different indices in meteorological, hydrological, and agricultural categories, respectively.

\subsection{Comparison of Categorical Drought Scores and MASH}

The linear mixed-effects model was used to evaluate the mean difference between categorical (CMI, CHI, CAI, CSHI) and MASH scores. The results indicate that among the categorical drought scores, only CMI and CHI have no significant difference (0.81) with each other (Table 2). However, when the standard deviation of the differences was calculated, the value was large (29.98). This means that even though there is no significant difference in average values of CMI and $\mathrm{CHI}$, their average values can be quite different due to the large standard deviation of the differences. Therefore, one of these indices cannot be used to represent both of them. 
Additionally, the MASH index did not show similar behavior to any of the categorical drought indices. This implies that the MASH is not biased toward any of the categorical drought indices while representing the overall drought conditions.

Table 2.

Table 3.

\subsection{Variable Selection}

The top five selected variables and their combinations for each drought category and MASH are presented in Table 4. As it was expected, the results indicate that variables related to precipitation data (Gamma-precipitation, Gamma P-PET, and precipitation percentile) were ranked the highest for the meteorological category. For the hydrological category, the variables obtained from streamflow (streamflow exceedance probability, log-normal streamflow, and severity index for a wet/dry spell) were mostly ranked as the highest variables. For the agricultural category, the variables obtained from evapotranspiration deficit (monthly water stress anomaly, monthly soil moisture deficit, and Gamma P-PET) were ranked the highest most often. Finally, for MASH, streamflow related variables (log-normal streamflow and streamflow exceedance probability) were ranked the highest while the precipitation related variable (precipitation percentile) came next. Overall, it can be concluded that precipitation, streamflow, and evapotranspiration variables have a high influence on meteorological, hydrological, and agricultural drought, respectively. Meanwhile for MASH, the streamflow variables have the highest influence on determining the overall drought.

Table 4. 


\subsection{Categorical and MASH drought models}

The best ANFIS models for each drought category and MASH, including their statistical analysis and ANFIS configuration, are presented in Table 5. For all best selected models using two variables, the Gaussian membership function and linear output membership function were selected. For the best models selected using three variables, triangular and generalized bell were selected in addition to Gaussian membership functions. However, trapezoidal and Gaussian composite membership functions were never selected. The dominant combination for the number of membership functions were 4,4 for two variables and 4, 4, 4 for three variables. The statistical analyses performed on the models were found to be generally acceptable and consistent in regard to $R^{2}$ and RMSE. The $R^{2}$ of the drought models range from 0.64 to 0.97 for two variables and from 0.75 to 0.98 for three variables. The meteorological and hydrological drought models have the highest $R^{2}$ of 0.91 and 0.97 using two variables and 0.95 and 0.98 using three variables, respectively. Furthermore, the RMSE values for both meteorological and hydrological drought models are low (below 10). Among the categorical drought models, the

agricultural drought model had the lowest $R^{2}$ value and the highest RMSE value. The MASH drought model had a $R^{2}$ of 0.72 and RMSE of 18.93 using two variables, and a $R^{2}$ of 0.75 and RMSE of 18.18 using three variables. It can be concluded that the predictive models developed from three variables are more reliable than those developed from two variables, due to higher $R^{2}$ and lower RMSE values.

\section{Table 5 .}

Overall, the histograms of measured scores are similar to the modeled ones. However, the predicted histogram of the agricultural model (CAI) has a higher peak compared to the measured histogram for both two and three variables models (Figures S3-c and 3-c, respectively). In the 
modeled histogram, the peak (the event with the highest frequency) occurred almost 8000 times; however, in the measured histogram, the peak occurred about 6000 times. This can be due to the high RMSE and low $R^{2}$ values of the agricultural model, which can results a shift in frequency classes. High variability in soil moisture deficit and Gamma P-PET can result in high RMSE in agricultural drought indices. The histograms for the MASH model looked better than the agricultural model, but still have different peak values. The modeled histogram has a higher peak value (more than 8000) than the measured histogram (less than 8000) for two variables. However, using for both agricultural and MASH models, three variables improved the peaks in the predicted histogram. Therefore, the use of additional and relevant variables can improve the predictability of both models.

Figure 3.

\subsection{Identifying the drought vulnerable areas}

In the Saginaw River Watershed, 9\% of the watershed was identified as high priority areas based on the MASH index (Figure 4). In order to compare the high priority areas of MASH with the categorical drought the term "match" was used to define overlap while "mismatch" defines not

overlap. The stream health category has the highest match $(69.85 \%)$ and the hydrological category had the lowest match $(9.23 \%)$. This indicates that $69.85 \%$ of high priority areas for the categorical stream health drought match the high priority areas of MASH; while only $9.23 \%$ of high priority areas of hydrological category match with the high priority areas of MASH. After the stream health category, the agricultural category has the highest match with $56.56 \%$, and the meteorological category has $10.29 \%$ match, which is fairly close to the hydrological category. Overall, the stream health category had the highest overlap with the MASH index. 
The percentages that each categorical drought score mismatched in identifying the high priority areas compared to MASH were also calculated. The results indicate that the agricultural category had the highest mismatch $(79.06 \%)$ and the stream health had the lowest mismatch (14.43\%). This shows that the agricultural category failed to identify the overall high priority areas $79.06 \%$ of the time, while the stream health category failed $14.43 \%$ of the time. Although the agricultural category was identified to have the second highest match percentage of $56.56 \%$, it also missed identifying high priority areas $79.06 \%$ of the time. Therefore, it can be concluded that the agricultural category is less representative of the overall drought condition identified by MASH. After the agriculture category, the hydrological and meteorological categories were identified to have the highest mismatch of $64.24 \%$ and $61.07 \%$, respectively.

Figure 4.

In general, it is important to note that mismatching of different categorical drought indices with MASH does not imply that those indices are more or less reliable than MASH. In fact, it is recommended to use categorical drought indices for conditions in which the goal of study is to address individual drought impacts (e.g. hydrological and agricultural). Meanwhile, MASH application is limited to evaluation of the overall drought conditions in which different aspects of drought (meteorological, hydrological, agricultural, and stream health) are equally important. For example, the categorical agricultural index should not be incorporated when calculating MASH during the dormant season.

\section{Conclusion}

For the meteorological and hydrological indices, the mean differences are small while the standard deviations are large. Meanwhile, for the agricultural indices, both mean and standard 
deviations are large. This indicates that the drought indices values for individual events can be quite different due to the large standard deviation even though the long-term mean differences were small for the meteorological and hydrological indices.

The results of this study indicated that precipitation, streamflow, and evapotranspiration were the most influential variables of meteorological, hydrological, and agricultural drought categories, respectively. In addition, the streamflow variables were selected as the top ranked variables for the overall drought.

The results of the predictive models using three input variables was better compared to using two input variables. The $R^{2}$ values were 0.95 for meteorological, 0.98 for hydrological, 0.77 for agricultural drought categories, and 0.75 for MASH.

The drought prone areas identified by MASH were compared with the drought prone areas identified by meteorological, hydrological, agricultural, and stream health categories. The results indicated that the stream health category had the highest match and the hydrological category has the lowest match compared to MASH. In addition, the agricultural category had the highest mismatch and the stream health had the lowest mismatch. Overall, the stream health category had the closest identification of high priority areas to MASH.

This study introduced a comprehensive drought index (MASH) capable of quantifying drought with respect to metrological, agricultural, stream health, and hydrological aspects. Future studies should include other aspects of drought such as economic and social, which can further improve the general understanding of drought impacts on human and natural systems. In addition, evaluation of other machine-learning methods can improve the drought model predictabilities. Finally, future studies should address some knowledge gaps for managing drought especially in 
the area of drought forecasting and spatial presentation using robust techniques that are not heavily parameter dependent.

\section{Acknowledgements}

This work is supported by the USDA National Institute of Food and Agriculture, Hatch project MICL02212.

\section{References}

Abatzoglou, J.T., 2013. Development of gridded surface meteorological data for ecological applications and modelling. International Journal of Climatology 33, 121-131.

Abbaspour, K.C., 2015. SWAT-CUP: SWAT calibration and uncertainty programs - a user manual. Available at: http://swat.tamu.edu/media/114860/usermanual_swatcup.pdf (accessed 4.1.16).

American Meteorological Society, 1997. Meteorological drought-Policy statement. Bulletin of the American Meteorological Society 78, 847-849.

Arnold, J.G., Srinivasan, R., Muttiah, R.S., Williams, J.R., 1998. Large area hydrologic model development and assessment part 1: model development. Journal of the American Water Resources Association 34, 73-89.

Bacanli, U.G., Firat, M., Dikbas, F., 2009. Adaptive neuro-fuzzy inference system for drought forecasting. Stochastic Environmental Research and Risk Assessment 23, 1143-1154.

Balint, Z., Mutua, F.M., Muchiri, P., 2011. Drought monitoring with the combined drought index. FAO-SWALIM: Nairobi, Kenya 3-25.

Barkstrom, B.R., 1984. The earth radiation budget experiment (ERBE). Bulletin of the American Meteorological Society 65, 1170-1185. 
Brown, J.F., Wardlow, B.D., Tadesse, T., Hayes, M.J., Reed, B.C., 2008. The Vegetation Drought Response Index (VegDRI): A new integrated approach for monitoring drought stress in vegetation. GIScience \& Remote Sensing 45, 16-46.

Dai, A., 2011. Drought under global warming: a review. Wiley Interdisciplinary Reviews: Climate Change 2, 45-65.

Einheuser, M.D., Nejadhashemi, A.P., Wang, L., Sowa, S.P., Woznicki, S.A., 2013. Linking biological integrity and watershed models to assess the impacts of historical land use and climate changes on stream health. Environmental management 51, 1147-1163.

El-Sebakhy, E.A., Raharja, I., Adem, S., Khaeruzzaman, Y., 2007. Neuro-fuzzy systems modeling tools for bacterial growth, in: IEEE/ACS International Conference on Computer Systems and Applications, pp. 374-380.

ENVIRON, 2007. Current conditions report for the Saginaw River, floodplain, and bay. Available at: http://www.michigan.gov/documents/deq/deq-whm-hwp-dow-9-2007-DraftCCR-SRB-Text_210867_7.pdf (accessed 10.13.16).

Esfahanian, E., Nejadhashemi, A. P., Abouali, M., Daneshvar, F., Ameli, A., Herman, M., Tang, Y.,2016. Defining Drought in the context of Stream Health. Ecological Engineering, Ecological Engineering 94, 668-681.

Ficklin, D.L., Letsinger, S.L., Gholizadeh, H., Maxwell, J.T., 2015. Incorporation of the Penman-Monteith potential evapotranspiration method into a Palmer Drought Severity Index Tool. Computers \& Geosciences 85, 136-141.

MathWorks, 2016. Fuzzy Logic Toolbox. Available at: http://www.mathworks.com/products/fuzzy-logic/ (accessed 4.12.16). 
Guttman, N.B., 1998. Comparing the Palmer Drought Index and the Standardized Precipitation Index1. JAWRA Journal of the American Water Resources Association 34, 113-121.

Hamaamin, Y.A., Nejadhashemi, A.P., Einheuser, M.D., 2013. Application of fuzzy logic techniques in estimating the regional index flow for Michigan. Transactions of the ASABE $56,103-115$.

Hamilton, D.A., Seelbach, P.W., 2011. Michigan's water withdrawal assessment process and internet screening tool. Fisheries Division Special Report 55.

Hayes, M.J., 2006. Drought indices. National Drought Mitigation Center. Available at: http://www.civil.utah.edu/ cv5450/swsi/indices.htm.

Hayes, M.J., Svoboda, M.D., Wilhite, D.A., 2000. Monitoring drought using the standardized precipitation index Drought, in: A Global Assessment, Vol. 1. Routledge, New York, pp. $168-180$.

Hayes, M.J., Svoboda, M.D., Wilhite, D.A., Vanyarkho, O.V., 1999. Monitoring the 1996 drought using the standardized precipitation index. Bulletin of the American Meteorological Society $80,429-438$.

Heim Jr, R.R., 2002. A review of twentieth-century drought indices used in the United States. Bulletin of the American Meteorological Society 83, 1149-1165.

Jacobi, J., Perrone, D., Duncan, L.L., Hornberger, G., 2013. A tool for calculating the Palmer drought indices. Water Resources Research 49, 6086-6089.

Jang, J.-S.R., 1993. ANFIS: adaptive-network-based fuzzy inference system. Systems, Man and Cybernetics, IEEE Transactions on 23, 665-685.

Kaehler, S.D., 2006. Fuzzy Logic Tutorial, the newsletter of Seattle Robotics Society (encoder). Available at: http://www.seattlerobotics.org/encoder/mar98/fuz/flindex.html 
Karamouz, M., Rasouli, K., Nazif, S., 2009. Development of a hybrid index for drought prediction: case study. Journal of Hydrologic Engineering 14, 617-627.

Keyantash, J.A., Dracup, J.A., 2004. An aggregate drought index: Assessing drought severity based on fluctuations in the hydrologic cycle and surface water storage. Water Resources Research 40.

Keyantash, J., Dracup, J.A., 2002. The quantification of drought: an evaluation of drought indices. Bulletin of the American Meteorological Society 83, 1167.

Kira, K., Rendell, L.A., 1992. A practical approach to feature selection, in: Proceedings of the Ninth International Workshop on Machine Learning. pp. 249-256.

Kisi, O., Karahan, M.E., Şen, Z., 2006. River suspended sediment modelling using a fuzzy logic approach. Hydrological Processes 20, 4351-4362.

Kononenko, I., 1994. Estimating attributes: analysis and extensions of RELIEF, in: Machine Learning: ECML-94. Springer, pp. 171-182.

Kuznetsova, A., Brockhoff, P.B., Christensen, R.H.B., 2016. lmerTest: tests in linear mixed effects models. R package version 2.0-30.

Marchini, A., 2011. Modelling ecological processes with fuzzy logic approaches, in: Modelling Complex Ecological Dynamics. Springer, pp. 133-145.

Martínez-Fernández, J., González-Zamora, A., Sánchez, N., Gumuzzio, A., 2015. A soil water based index as a suitable agricultural drought indicator. Journal of Hydrology 522, 265273.

Mishra, A.K., Singh, V.P., 2010. A review of drought concepts. Journal of Hydrology 391, 202216. 
Moorhead, J.E., Gowda, P.H., Singh, V.P., Porter, D.O., Marek, T.H., Howell, T.A., Stewart, B.A., 2015. Identifying and Evaluating a Suitable Index for Agricultural Drought Monitoring in the Texas High Plains. JAWRA Journal of the American Water Resources Association 51, 807-820.

Moriasi, D.N., Arnold, J.G., Van Liew, M.W., Bingner, R.L., Harmel, R.D., Veith, T.L., 2007. Model evaluation guidelines for systematic quantification of accuracy in watershed simulations. Transactions of the ASABE 50, 885-900.

Narasimhan, B., Srinivasan, R., 2005. Development and evaluation of Soil Moisture Deficit Index (SMDI) and Evapotranspiration Deficit Index (ETDI) for agricultural drought monitoring. Agricultural and Forest Meteorology 133, 69-88.

NDMC, 2016. Types of Drought. Available at: http://drought.unl.edu/DroughtBasics/TypesofDrought.aspx (accessed 4.12.16).

NED, 2014. National Elevation Dataset. Available at: http://nationalmap.gov/elevation.html (accessed 4.12.16).

Palmer, W.C., 1965. Meteorological drought. US Department of Commerce, Weather Bureau Washington, DC, USA.

Pinheiro, J., Bates, D., 2006. Mixed-effects models in S and S-PLUS. Springer Science \& Business Media.

PSC, 2012. Saginaw Bay Watershed and Area of Concern. Prepared by Public Sector Consultants, Inc. for the Planning \& Zoning Center at MSU as part of a Great Lakes Restoration Initiative project. Lansing, MI. Available at: http://www.pscinc.com/LinkClick.aspx?fileticket=Hi_PFZU-xOI\%3D\&tabid=65 (accessed $3.01 .16)$ 
Robnik-Šikonja, M., Kononenko, I., 2003. Theoretical and empirical analysis of ReliefF and RReliefF. Machine learning 53, 23-69.

Selzer, M.D., Joldersma, B., Beard, J., 2014. A reflection on restoration progress in the Saginaw Bay watershed. Journal of Great Lakes Research 40, 192-200.

Sheffield, J., Wood, E.F., 2012. Drought: past problems and future scenarios. London, Washington:Earthscan.

Shukla, S., Wood, A.W., 2008. Use of a standardized runoff index for characterizing hydrologic drought. Geophysical Research Letters 35.

Svoboda, M., LeComte, D., Hayes, M., Heim, R., others, 2002. The drought monitor. Bulletin of the American Meteorological Society 83, 1181-1190.

Tadesse, T., Wardlow, B., 2007. The vegetation outlook (VegOut): a new tool for providing outlooks of general vegetation conditions using data mining techniques. In seventh IEEE International Conference on Data Mining Workshops (ICDM Workshops), IEEE, pp. 667672.

Takagi, T., Sugeno, M., 1985. Fuzzy identification of systems and its applications to modeling and control. Systems, Man and Cybernetics, IEEE Transactions on 116-132.

Tallaksen, L.M., Van Lanen, H.A., 2004. Hydrological drought: processes and estimation methods for streamflow and groundwater. Developments in Water Sciences 48, Elsevier B.V., Amesterdam.

Tsakiris, G., Loukas, A., Pangalou, D., Vangelis, H., Tigkas, D., Rossi, G., Cancelliere, A., others, 2007. Drought characterization. Drought management guidelines technical annex $85-102$.

U.S. climate data, 2016. Available at: http://www.usclimatedata.com/ (accessed 2.2.16). 
USDA-NASS, 2011. National Agriculture Statistic Services. Available at:

http://www.nass.usda.gov/Statistics_by_State/Michigan/Publications/Annual_Statistical_Bu lletin/stats11/cntyrnk.pdf (accessed 3.01.16).

USEPA, 2011. An approach for estimating stream health using flow duration curves and indices of hydrologic alteration. AgriLIFE RESEARCH \& EXTENSION, Texas A\&M System, 2124.

Vannote, R.L., Minshall, G.W., Cummins, K.W., Sedell, J.R., Cushing, C.E., 1980. The river continuum concept. Canadian journal of fisheries and aquatic sciences 37, 130-137.

Vasiliades, L., Loukas, A., Liberis, N., 2011. A water balance derived drought index for Pinios River Basin, Greece. Water Resources Management 25, 1087-1101.

NRCS, 2014.Web Soil Survey. Available at: http://websoilsurvey.sc.egov.usda.gov/App/WebSoilSurvey.aspx (accessed 4.12.16).

Whitmore, J.S., 2000. Drought management on farmland. Springer Science \& Business Media.

Wilhite, D.A., 2000. Drought as a natural hazard: concepts and definitions in: A Global Assessment, Vol. 1. Routledge, New York, pp. 1-18.

Wilhite, D.A., Sivakumar, M.V., Pulwarty, R., 2014. Managing drought risk in a changing climate: The role of national drought policy. Weather and Climate Extremes 3, 4-13.

Woznicki, S.A., Nejadhashemi, A.P., Abouali, M., Herman, M.R., Esfahanian, E., Hamaamin, Y.A., Zhang, Z., 2016. Ecohydrological modeling for large-scale environmental impact assessment. Science of The Total Environment 543, 274-286.

Woznicki, S.A., Nejadhashemi, A.P., Ross, D.M., Zhang, Z., Wang, L., Esfahanian, A.-H., 2015. Ecohydrological model parameter selection for stream health evaluation. Science of The Total Environment 511, 341-353. 
Zargar, A., Sadiq, R., Naser, B., Khan, F.I., 2011. A review of drought indices. Environmental Reviews 19, 333-349.

Ziese, M., Schneider, U., Meyer-Christoffer, A., Schamm, K., Vido, J., Finger, P., Bissolli, P., Pietzsch, S., Becker, A., 2014. The GPCC Drought Index-a new, combined and gridded global drought index. Earth System Science Data 6, 285-295.

Zorn, T.G., Seelbach, P.W., Rutherford, E.S., 2012. A Regional-Scale Habitat Suitability Model to Assess the Effects of Flow Reduction on Fish Assemblages in Michigan Streams1. JAWRA Journal of the American Water Resources Association 48, 871-895. 


\section{Figure Captions}

Figure 1. Saginaw River Watershed

Figure 2. Categorical drought scores development and modeling process

Figure 3. Measured versus modeled histograms of categorical drought and MASH: (a) categorical meteorological index, (b) categorical hydrological index, (c) categorical agricultural index, and (d) MASH

Figure 4. Drought vulnerable areas based on categorical drought indices in the Saginaw River watershed: (a) meteorological, (b) hydrological, (c) agricultural, (d) stream health and (e) MASH 


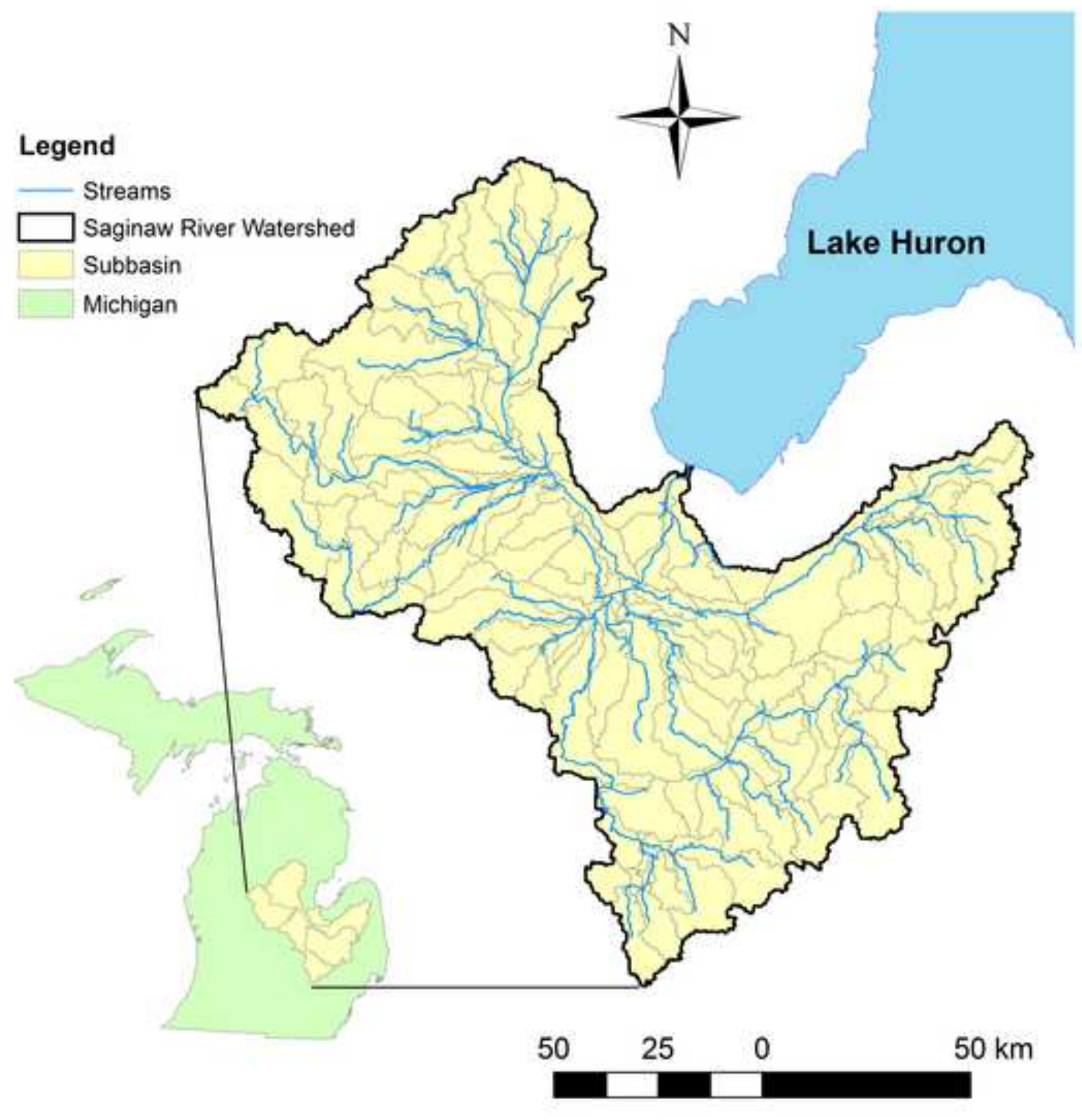

Legend

\section{Su}

M
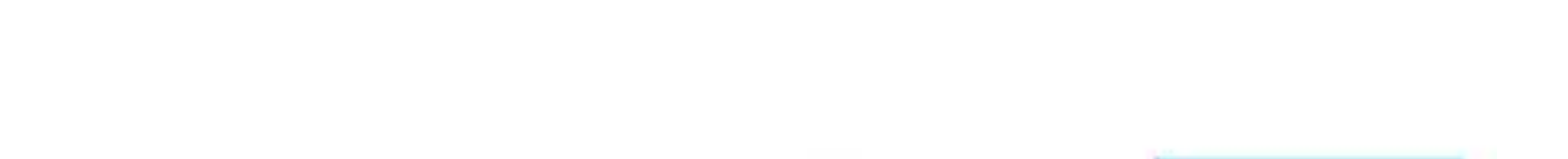


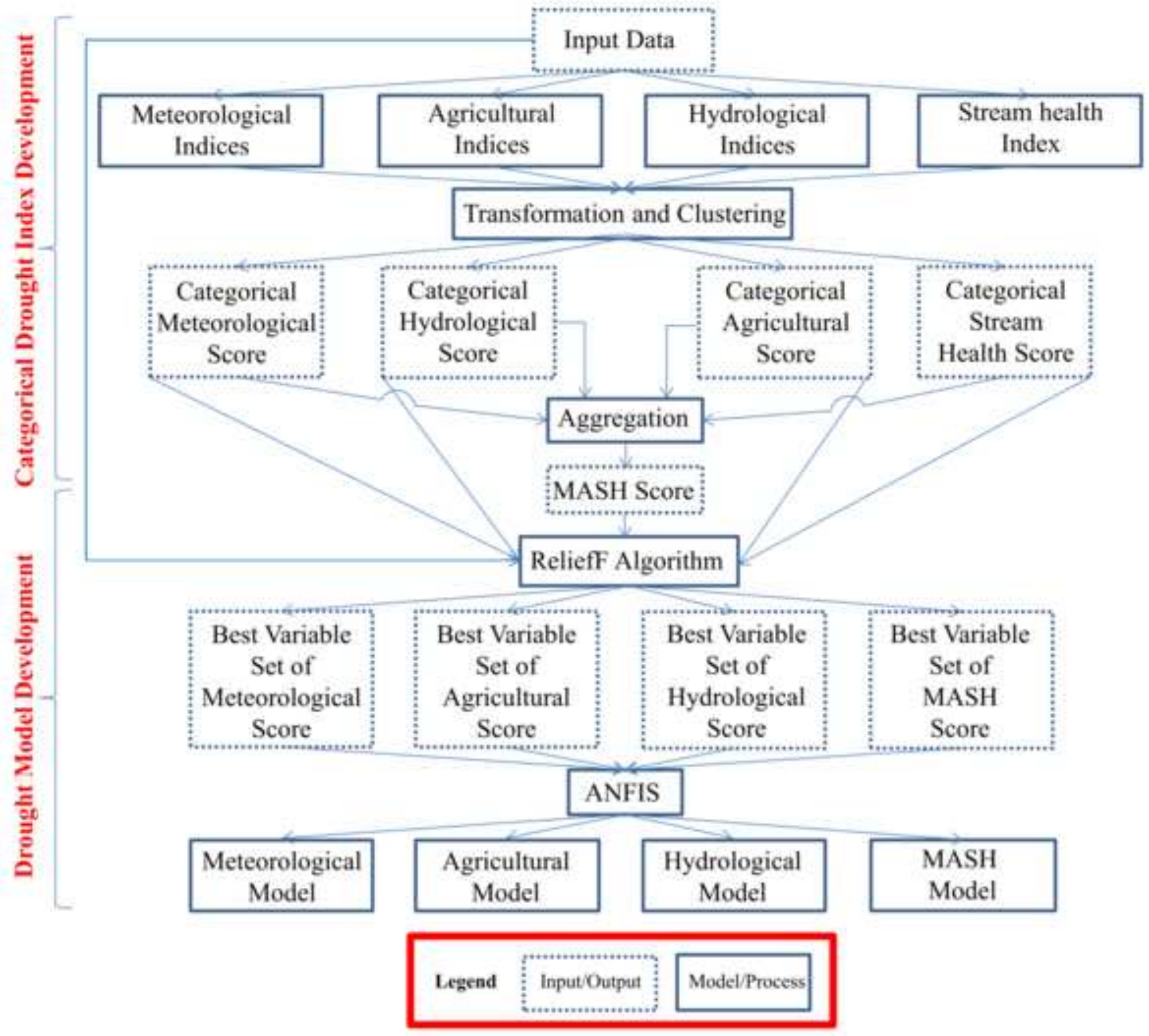



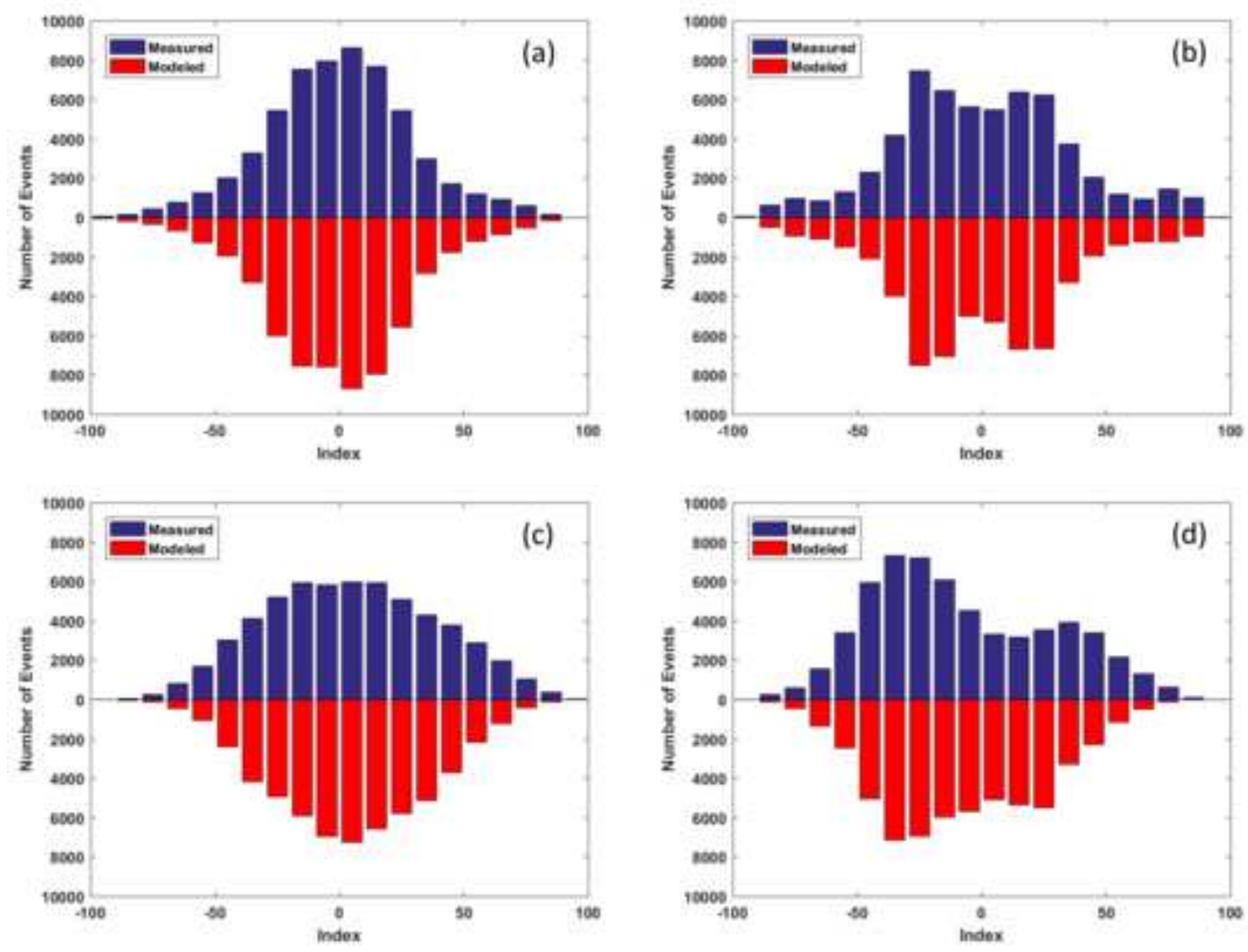
(a)

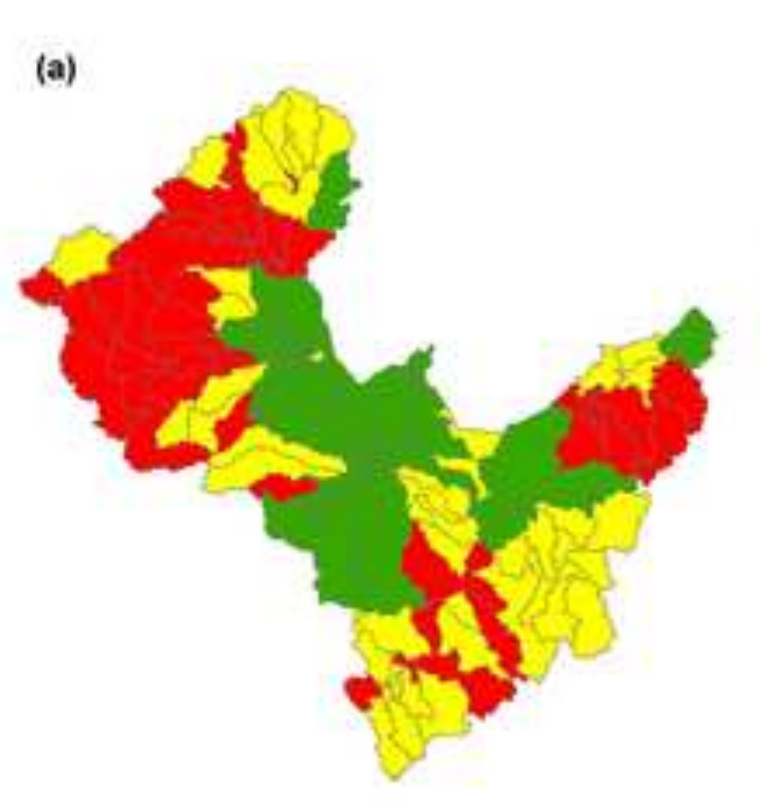

(b)

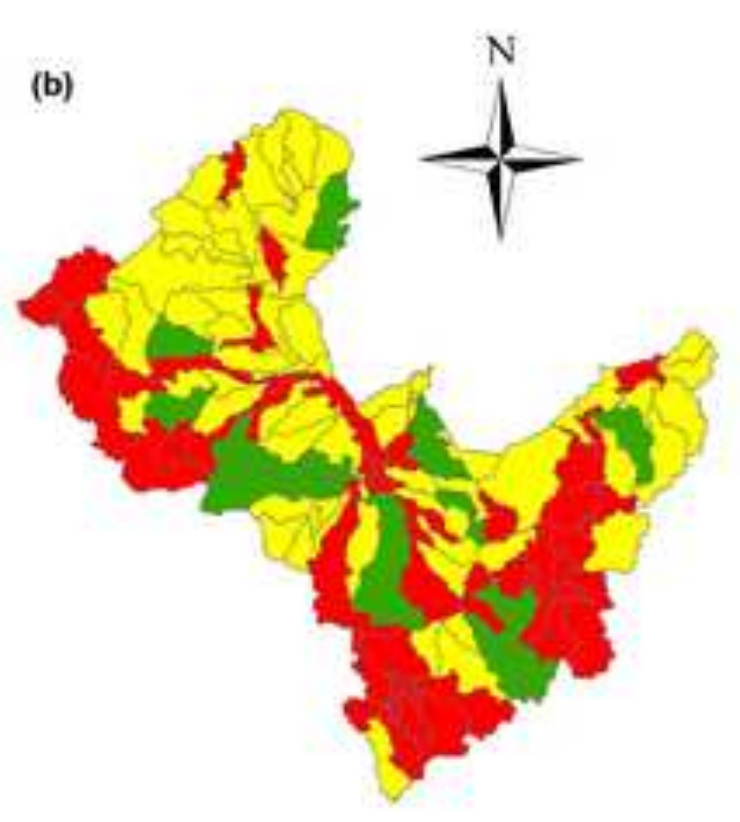

(c)

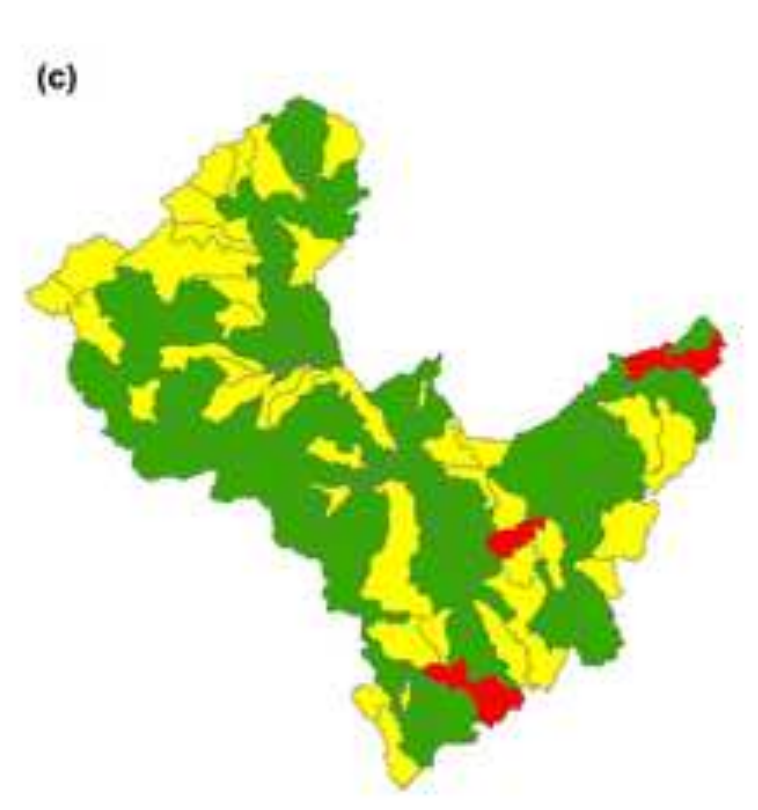

(d)

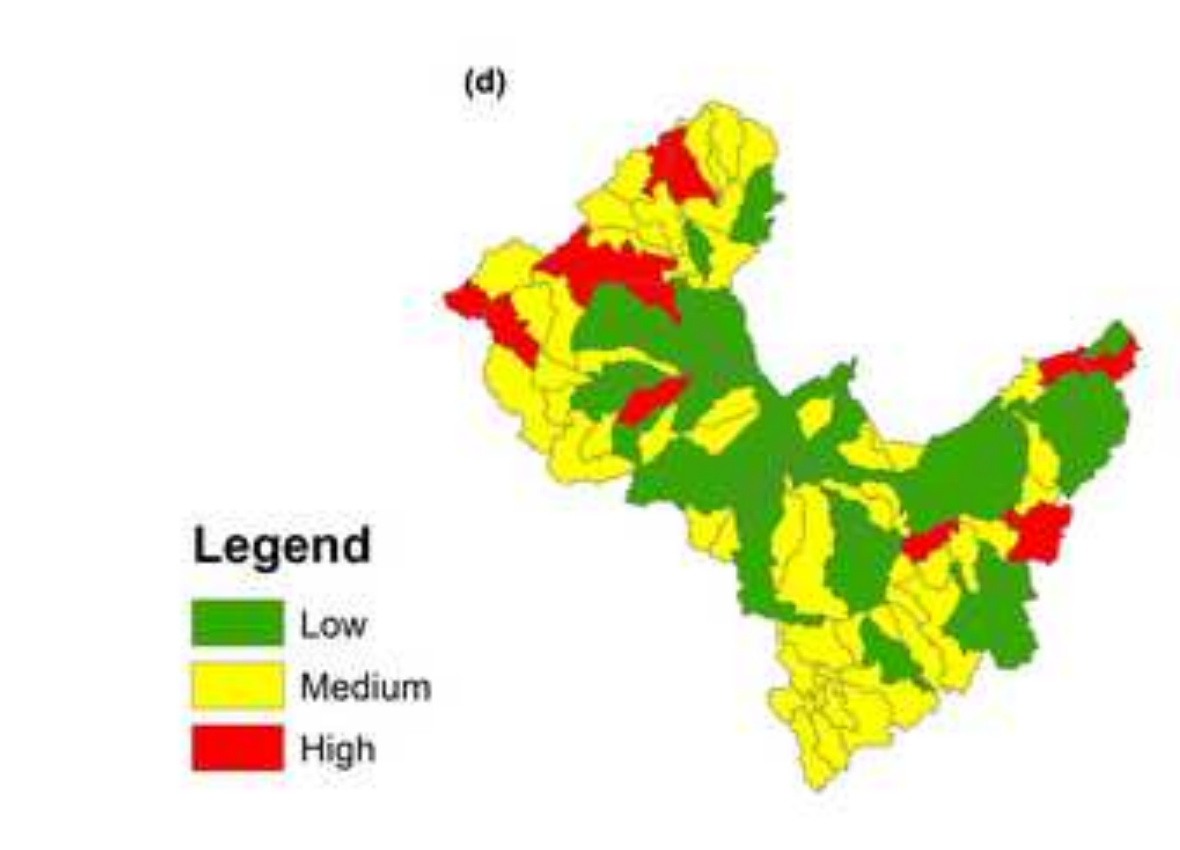

(e)

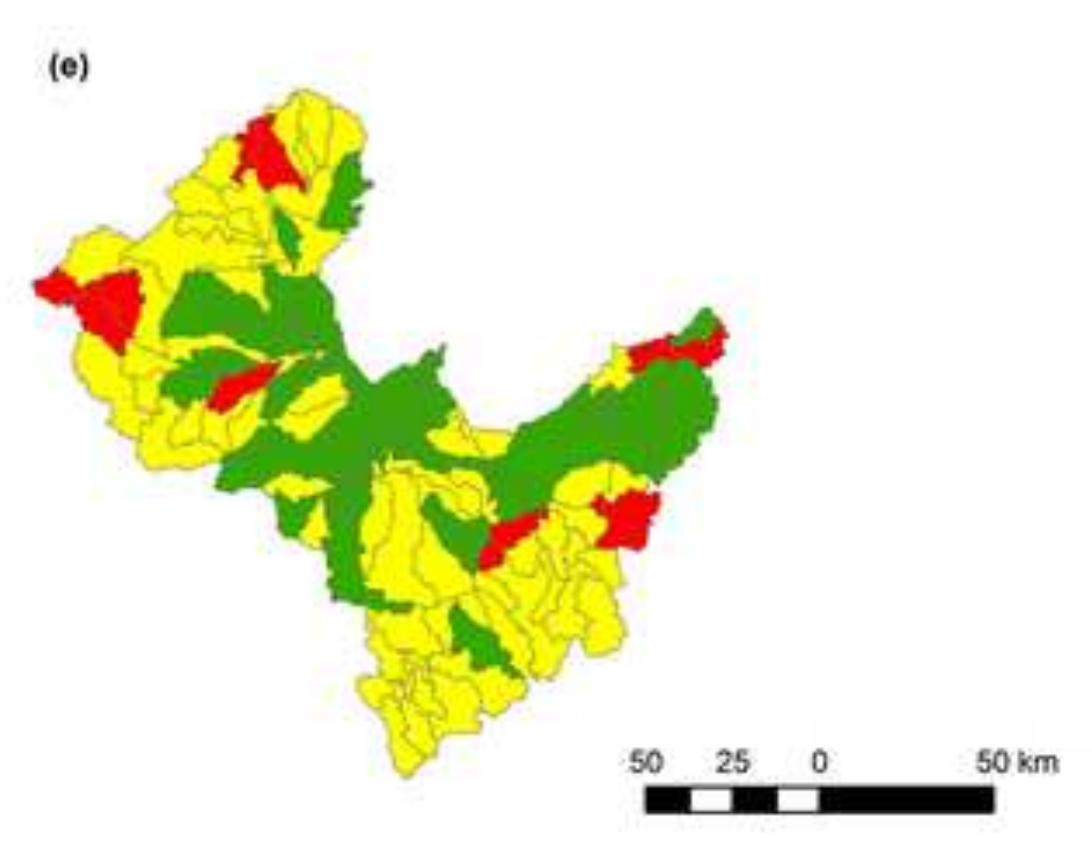


Table 1. ANFIS models frameworks and characteristics

\begin{tabular}{cccccc}
\hline $\begin{array}{c}\text { Number } \\
\text { of input } \\
\text { variables }\end{array}$ & $\begin{array}{c}\text { Possible } \\
\text { combinations } \\
\text { of input } \\
\text { variables }\end{array}$ & $\begin{array}{c}\text { Number of } \\
\text { membership } \\
\text { functions }\end{array}$ & $\begin{array}{c}\text { Membership } \\
\text { function } \\
\text { shapes }\end{array}$ & $\begin{array}{c}\text { Output } \\
\text { membership } \\
\text { function }\end{array}$ & $\begin{array}{c}\text { Sum of } \\
\text { combinations }\end{array}$ \\
\hline 2 & 10 & 3 & 5 & 2 & 900 \\
3 & 10 & 3 & 5 & 2 & 2,700 \\
\hline
\end{tabular}


Table 2. p-values from pairwise comparison of drought indices. Red colored p-values indicate no significant mean differences at the 0.05 level.

\begin{tabular}{|c|c|c|c|c|c|c|c|c|c|c|c|c|c|c|c|c|c|}
\hline \multirow{2}{*}{ Drought Index } & \multicolumn{5}{|c|}{ Meteorological } & \multicolumn{5}{|c|}{ Hydrological } & \multicolumn{5}{|c|}{ Agricultural } & \multirow{2}{*}{$\frac{\text { Stream Health }}{\text { CSHI }}$} & \multirow{2}{*}{$\begin{array}{l}\text { Overall } \\
\text { MASH }\end{array}$} \\
\hline & PDSI & $\mathrm{RD}$ & SPI & RDI & CMI & PHDI & FDC & SRI & WBI & $\mathrm{CHI}$ & Z-Index & SMDI & ETDI & SWDI & CAI & & \\
\hline \multicolumn{18}{|l|}{ PDSI } \\
\hline $\mathrm{RD}$ & 0.43 & & & & & & & & & & & & & & & & \\
\hline SPI & 0.98 & 0.58 & & & & & & & & & & & & & & & \\
\hline RDI & 0.96 & 0.59 & 0.94 & & & & & & & & & & & & & & \\
\hline CMI & 0.85 & 0.56 & 0.78 & 0.81 & & & & & & & & & & & & & \\
\hline PHDI & 0.03 & 0.91 & 0.39 & 0.39 & 0.32 & & & & & & & & & & & & \\
\hline FDC & 0.95 & 0.48 & 0.98 & 0.99 & 0.94 & 0.33 & & & & & & & & & & & \\
\hline SRI & 0.88 & 0.45 & 0.93 & 0.95 & 0.96 & 0.23 & 0.95 & & & & & & & & & & \\
\hline $\mathrm{CHI}$ & 0.97 & 0.38 & 0.95 & 0.94 & 0.81 & 0.17 & 0.88 & 0.39 & 0.09 & & & & & & & & \\
\hline Z-Index & 0.46 & 0.33 & 0.22 & 0.19 & 0.052 & 0.11 & 0.56 & 0.36 & 0.75 & 0.47 & & & & & & & \\
\hline SMDI & $6 e-06$ & 0.03 & 0.003 & 0.003 & 0.0003 & 0.008 & 0.0004 & $4 \mathrm{e}-06$ & 0 & $1 \mathrm{e}-06$ & $4.1 \mathrm{e}-05$ & & & & & & \\
\hline ETDI & 0.04 & 0.47 & 0.04 & 0.04 & 0.02 & 0.43 & 0.11 & 0.02 & 0.003 & 0.02 & 0.003 & 0.08 & & & & & \\
\hline SWDI & 0 & 0 & 0 & 0 & 0 & 0 & 0 & 0 & 0 & 0 & 0 & 0 & 0 & & & & \\
\hline CAI & $3 e-06$ & 0.002 & $2 \mathrm{e}-05$ & $1.5 \mathrm{e}-05$ & 0 & $2 e-06$ & 0.0004 & 0 & $1 e-06$ & 0 & $2 \mathrm{e}-06$ & 0 & 0 & 0 & & & \\
\hline CSHI & 0 & 0 & 0 & 0 & 0 & 0 & 0 & 0 & 0 & 0 & 0 & 0 & 0 & 0 & 0 & & \\
\hline MASH & 0 & 8.6e-05 & 0 & 0 & 0 & 0 & 0 & 0 & 0 & 0 & 0 & 0.0006 & $6 e-06$ & 0 & 0 & 0 & \\
\hline
\end{tabular}


Table 3. Frequency of drought indices combinations in each drought category over 30-year period

\begin{tabular}{|c|c|c|c|c|c|c|c|c|c|c|c|c|c|c|c|}
\hline \multirow{2}{*}{$\begin{array}{l}\text { Combinations } \\
\text { ranking }\end{array}$} & \multicolumn{4}{|c|}{ Meteorological Indices } & \multirow[b]{2}{*}{$\begin{array}{c}\text { Frequency } \\
(\%)\end{array}$} & \multicolumn{4}{|c|}{ Hydrological Indices } & \multirow[b]{2}{*}{$\begin{array}{c}\text { Frequency } \\
(\%)\end{array}$} & \multicolumn{4}{|c|}{ Agricultural Indices } & \multirow[b]{2}{*}{$\begin{array}{c}\text { Frequency } \\
(\%)\end{array}$} \\
\hline & PDSI & $\mathrm{RD}$ & SPI & RDI & & PHDI & FDC & SRI & WBI & & Z-index & SMDI & ETDI & SWDI & \\
\hline First & $\mathrm{x}$ & & $\mathrm{x}$ & $\mathrm{x}$ & 62.70 & & $\mathrm{x}$ & $\mathrm{x}$ & $\mathrm{x}$ & 49.68 & $\mathrm{x}$ & $\mathrm{x}$ & $\mathrm{x}$ & & 69.44 \\
\hline Second & & $\mathrm{x}$ & $\mathrm{x}$ & $\mathrm{x}$ & 26.16 & $\mathrm{x}$ & & $\mathrm{x}$ & $\mathrm{x}$ & 41.71 & $\mathrm{x}$ & & $\mathrm{x}$ & $\mathrm{x}$ & 12.21 \\
\hline Third & $\mathrm{x}$ & $\mathrm{x}$ & & $\mathrm{x}$ & 5.94 & $\mathrm{x}$ & $\mathrm{x}$ & $\mathrm{x}$ & & 4.92 & $\mathrm{x}$ & $\mathrm{x}$ & & $\mathrm{x}$ & 9.86 \\
\hline Fourth & $\mathrm{x}$ & $\mathrm{x}$ & $\mathrm{x}$ & & 5.18 & $\mathrm{x}$ & $\mathrm{x}$ & & $\mathrm{x}$ & 3.68 & & $\mathrm{x}$ & $\mathrm{x}$ & $\mathrm{x}$ & 8.49 \\
\hline Fifth & $\mathrm{X}$ & $\mathrm{x}$ & $\mathrm{x}$ & $\mathrm{x}$ & 0.02 & $\mathrm{x}$ & $\mathrm{x}$ & $\mathrm{x}$ & $\mathrm{x}$ & 0.01 & $\mathrm{x}$ & $\mathrm{x}$ & $\mathrm{x}$ & $\mathrm{x}$ & 0.00 \\
\hline
\end{tabular}


Table 4. Top five ranked variables that were used for development of the drought predictive models.

\begin{tabular}{|c|c|c|}
\hline Category & Ranked & Variables \\
\hline \multirow[t]{5}{*}{ Meteorological } & 1 & Gamma-precipitation \\
\hline & 2 & Gamma P-PET ${ }^{* * *}$ \\
\hline & 3 & Precipitation percentile ${ }^{* *}$ \\
\hline & 4 & Dry/wet spell severity index ${ }^{*, * *}$ \\
\hline & 5 & Precipitation \\
\hline \multirow[t]{5}{*}{ Hydrological } & 1 & Streamflow exceedance probability ${ }^{* *}$ \\
\hline & 2 & Log-normal streamflow ${ }^{*}, * *$ \\
\hline & 3 & Severity index for an established wet/dry spell ${ }^{*, * *}$ \\
\hline & 4 & Dry/wet spell severity index \\
\hline & 5 & Precipitation percentile \\
\hline \multirow[t]{5}{*}{ Agricultural } & 1 & Monthly water stress anomaly ${ }^{* * *}$ \\
\hline & 2 & Monthly soil moisture deficit ${ }^{* * *}$ \\
\hline & 3 & Gamma P-PET ${ }^{* *}$ \\
\hline & 4 & Gamma-precipitation \\
\hline & 5 & Precipitation percentile \\
\hline \multirow[t]{5}{*}{ MASH } & 1 & Log-normal streamflow ${ }^{* * *}$ \\
\hline & 2 & Streamflow exceedance probability \\
\hline & 3 & Precipitation percentile \\
\hline & 4 & Gamma-precipitation ${ }^{* * *}$ \\
\hline & 5 & Monthly water stress anomaly $^{* *}$ \\
\hline
\end{tabular}

* The best two variables set used in developing the final ANFIS drought models

*** The best three variables set used in developing the final ANFIS drought models 
Table 5. Best ANFIS models for each drought category and MASH

\begin{tabular}{lcccccc}
\hline \multirow{2}{*}{$\begin{array}{l}\text { Drought } \\
\text { Model }\end{array}$} & $\begin{array}{c}\text { Number of } \\
\text { Variables }\end{array}$ & \begin{tabular}{c} 
ANFIS Configuration \\
\cline { 3 - 5 }
\end{tabular} & $\begin{array}{c}\text { Shape } \\
\text { MFs }^{4}\end{array}$ & $\left(\right.$ MFs $\left.^{4}\right)$ & $\begin{array}{c}\text { Output } \\
\text { RMSE }\end{array}$ & \multirow{2}{*}{$R^{2}$} \\
\hline Meteorological & 2 & Gauss $^{1}$ & $(4,4)$ & Linear & 8.87 & 0.91 \\
& 3 & Bell $^{2}$ & $(4,4,4)$ & Linear & 6.18 & 0.95 \\
Hydrological & 2 & Gauss & $(4,3)$ & Linear & 6.29 & 0.97 \\
& 3 & Gauss & $(4,4,4)$ & Linear & 4.82 & 0.98 \\
Agricultural & 2 & Gauss & $(4,4)$ & Linear & 20.53 & 0.64 \\
& 3 & Triangle $^{3}$ & $(4,4,4)$ & Linear & 16.32 & 0.77 \\
MASH & 2 & Gauss & $(4,4)$ & Linear & 18.93 & 0.72 \\
& 3 & Gauss & $(4,4,4)$ & Linear & 18.18 & 0.75 \\
\hline
\end{tabular}

${ }^{1}$ Gaussian; ${ }^{2}$ Generalized bell; ${ }^{3}$ Triangular; ${ }^{4}$ Membership functions 